\title{
Simple Preparation of $\mathrm{Co}_{3} \mathrm{O}_{4}$ with a Controlled Shape and Excellent Lithium Storage Performance
}

\author{
Yingjie Zhang ${ }^{1}$, Huaicong Yan ${ }^{1}$, Jiaming Liu ${ }^{2}$, Xue Li $^{1,}$,, Yiyong Zhang, ${ }^{1, *}$ \\ ${ }^{1}$ National and Local Joint Engineering Laboratory for Lithium-ion Batteries and Materials Preparation \\ Technology, Faculty of Metallurgical and Energy Engineering, Kunming University of Science and \\ Technology, Kunming 650093, PR China \\ ${ }^{2}$ School of Metallurgy and Chemistry Engineering, Jiangxi University of Science and Technology, \\ Ganzhou 341000, PR China \\ *E-mail: $\underline{438616074 @ q q . c o m}, \underline{810543061 @ q q . c o m}$
}

doi: $10.20964 / 2020.04 .35$

Received: 3 January 2020 / Accepted: 9 February 2020 / Published: 10 March 2020

$\mathrm{Co}_{3} \mathrm{O}_{4}$ and $\mathrm{Co}(\mathrm{OH})_{2}$ precursors with spherical and a coexisting sheet-spherical morphologies were efficiently prepared using room-temperature deposition combined with calcination. Compared with spherical $\mathrm{Co}_{3} \mathrm{O}_{4}$, coexisting sheet-spherical $\mathrm{Co}_{3} \mathrm{O}_{4}$ has better crystallinity and outstanding lithium storage performance. The first discharge capacity reaches $1089 \mathrm{mAh} \mathrm{g}^{-1}$. The charging capacity is 604 $\mathrm{mAh} \mathrm{g}^{-1}$, demonstrating a 50 -cycle capacity retention of $70 \%$. The enhanced lithium-ion storage capacity is attributed to the two-dimensional structure of the coexisting sheet and spherical morphology contained in the sheet material; additionally, the surface has a large surface area. Thus, the coexisting sheet-spherical morphology can alleviate the volume expansion caused by lithium-ion insertion, while retaining a high capacity and good cycling performance.

Keywords: $\mathrm{Co}_{3} \mathrm{O}_{4}$, Sheet and spherical, Two-dimensional, Lithium ion battery

\section{$\underline{\text { FULL TEXT }}$}

(C) 2020 The Authors. Published by ESG (www.electrochemsci.org). This article is an open access article distributed under the terms and conditions of the Creative Commons Attribution license (http://creativecommons.org/licenses/by/4.0/). 